\title{
Antioxidant properties of Enterobacter cloacae C3 lipopeptides in vitro and in model food emulsion
}

\author{
Noomen Hmidet $^{1}$ (D) | Nawel Jemil ${ }^{1}$ | Manel Ouerfelli, ${ }^{2,3}$ | María Pilar Almajano ${ }^{3}$ | \\ Moncef Nasri ${ }^{1}$
}

${ }^{1}$ Laboratoire de Génie Enzymatique et de Microbiologie, Ecole Nationale d'Ingénieurs de Sfax, Université de Sfax, Sfax, Tunisia

${ }^{2}$ Research Unit « Nutrition et Métabolisme Azotés et Protéines de Stress » (UR/ ES-13/29), Biology Department, Faculty of Sciences of Tunis, University of Tunis ElManar, Tunis, Tunisia

${ }^{3}$ School of Industrial Engineering of Barcelona (ETSEIB), Chemical Engineering Department (DEQ), Technical University of Catalonia (UPC), Barcelona, Spain

Correspondence

Noomen Hmidet, Laboratoire de Génie Enzymatique et de Microbiologie, Ecole Nationale d'Ingénieurs de Sfax, Université de Sfax, B.P. 1173-3038 Sfax, Tunisia.

Email: hmidet_noomen@yahoo.fr

Funding information

This work was funded by the Ministry of Higher Education and Scientific Research, Tunisia

\begin{abstract}
The present work aims to investigate the in vitro antioxidant activities of Enterobacter cloacae C3 lipopeptides, as well as the stability of sunflower oil in water (o/w) emulsion and the conservation of raw beef patties. The C 3 lipopeptides were assayed for their antioxidant activity through five different tests. The C3 lipopeptides showed good in vitro antioxidant activities. Lipopeptides $\mathrm{C} 3$ exhibited important antioxidant properties in $10 \%$ sunflower o/w emulsions during prolonged storage (28 days) at $30^{\circ} \mathrm{C}$. The effect of $\mathrm{C} 3$ lipopeptides on the oxidative stability of raw beef patties showed effectiveness effect in preventing oxidative degradation of lipids via thiobarbituric acid reactive substance and peroxide methods. Cytotoxicity test using human kidney HEK293 cells showed that studied lipopeptides was nontoxic substances. The results of this study indicate that lipopeptides $\mathrm{C} 3$ could be appropriate antioxidant agent in food models as inhibitors of lipid oxidation.

\section{Practical applications}

Lipid oxidation is considered to be one of the major causes of quality deterioration in natural and processed foods. Lipopeptides produced by E. cloacae C3 could be appropriate for use as natural antioxidants and could be considered as alternative to synthetic antioxidants for the preservation of o/w emulsions and meat against lipid oxidation for a long period.
\end{abstract}

\section{1 | INTRODUCTION}

Lipid oxidation was considered to be the main cause of food degradation and the reduction of some properties like the commercial shelf life, sensory properties (undesirable flavors, odors, dark colors, and so on), and consumer acceptability (Wąsowicz et al., 2004). Furthermore, cancer, coronary heart disease, and Alzheimer's diseases are also reported to be caused in part by oxidation or free radical reactions in the body (Liguori et al., 2018).

To prevent foods from undergoing such deterioration and to provide protection against serious diseases, it is very important to inhibit lipid peroxidation occurring in food stuffs and the living body via utilization of antioxidant molecules. In fact, antioxidant is defined as any molecule that significantly delays or inhibits oxidation of a substance when present at low concentration compared to that of an oxidizable substrate. These molecules are used to preserve food products by retarding discoloration and deterioration as a result of oxidation.

Synthetic phenolic antioxidants, such as Butylated Hydroxyanisole (BHA), have been used as effective additives to control lipid oxidation in high fat content foods. However, an increasing concern about their safety has resulted in a preferential research on natural antioxidants.

To overcome these drawbacks, many natural molecules were studied for their antioxidant activities like protein hydrolysates from animal, plant, and aquatic products (Hmidet et al., 2011; Nasri et al., 2012). Among these biomolecules, biosurfactants were described for their antioxidant properties (Ben Ayed et al., 2015; Ben Ayed, Hmidet, Béchet, Jacques, \& Nasri, 2017; Jemil, Ben Ayed, 
Manresa, Nasri, \& Hmidet, 2017) and emulsions stabilization (Bai \& McClements, 2016; Pekdemir, Çopur, \& Urum, 2005).

In fact, biosurfactants have emerged as multifunctional molecules due to their structures diversity, as well as diverse properties and wide range of industrial applications (Marchant \& Banat, 2012). In comparison with synthetic surfactants, they present some advantages like low toxicity, high biodegradability, environmental compatibility, high foaming, wide selectivity, and specific activity at extreme temperature, $\mathrm{pH}$, and salinity (Desai \& Banat, 1997). These properties allow using them in various industries detergents, textiles, paints, mining, cellulose, pharmaceutics, and nanotechnology (Rodrigues, Banat, Teixeira, \& Oliveira, 2006).

On the basis of their chemical structures, biosurfactants are divided into five major classes: lipopeptides, glycolipids, phospholipids, neutral lipids, and polymeric compounds (Desai \& Banat, 1997). Microbial lipopeptides are amphiphilic secondary metabolites composed of one fatty acid chain linked to a peptide moiety (Jacques, 2011). These bioactive compounds are produced by a set of microorganisms mainly present in the soil (Coutte et al., 2017). Actually, lipopeptides are predominantly used in bioremediation of pollutants (Karlapudi et al., 2018), pharmaceutical (Gharaei-Fathabad, 2011), and cosmetic industries (Vecino, Cruz, Moldes, \& Rodrigues, 2017); however, these microbial compounds exhibit a variety of useful properties for application in many sectors of food industry specially as antioxidant, antimicrobial, antiadhesive agents (Jemil et al., 2017), foaming, wetting, solubilizers, and emulsifiers (Banat, Makkar, \& Cameotra, 2000). In fact, emulsifiers are used, as emulsions stabilizers, in different industries like paint, food, cosmetic, and pharmaceutical.

In our previous work, during a screening program of novel biosurfactants producing strains, Jemil, Hmidet, Ben Ayed, and Nasri (2018) studied the physicochemical properties of biosurfactants produced by a newly isolated strain E. cloacae C3, as well their application in diesel oil solubilization. This strain produces a mixture of kurstakin and surfactin isoforms. The produced lipopeptides exhibited interesting antimicrobial activity, antiadhesive, and disruptive properties against biofilm formation by some human pathogenic bacterial strains (Jemil, Hmidet, Manresa, Rabanal, \& Nasri, 2019).

In this work, the in vitro antioxidant properties of E. cloacae C3 lipopeptides were evaluated using different tests. Their effects as natural protectors against lipid oxidation reactions in oil in water (o/w) emulsions and raw beef patties were also investigated.

\section{2 | MATERIALS AND METHODS}

\section{1 | Chemicals and reagents}

BHA, 1,1-diphenyl-2-picrylhydrazyl (DPPH), ethylenediaminetetraacetic acid (EDTA), ascorbic acid, and ferrozine were purchased from Sigma Chemical Co (St. Louis, MO, USA). All other chemicals, namely Ferric Chloride (MP Biomedicals fisher scientific, France), trichloroacetic acid (TCA) (Loba chemie, India), thiobarbituric acid (SUVCHEM, India), and other solvents, were of analytical grade.

\section{2 | Lipopeptides production and extraction}

E. cloacae C3 strain, selected for its lipopeptides production (Jemil et al., 2018), was used in this work. Inocula were routinely grown in Luria-Bertani (LB) broth medium composed of $(\mathrm{g} / \mathrm{L})$ peptone, 10; yeast extract, 5; and $\mathrm{NaCl}, 5$ (Miller, 1972). Landy medium (Landy, Warren, Rosenman, \& Colio, 1948) was used for lipopeptides production. Incubation was carried out with agitation at $150 \mathrm{rpm}$ and $30^{\circ} \mathrm{C}$ for $72 \mathrm{hr}$.

Lipopeptides extract was obtained from the cell free supernatant using acid precipitation followed by solvent extraction. In fact, the supernatant was acidifed with $\mathrm{HCl}(6 \mathrm{~N})$ to $\mathrm{pH} 2.0$ and incubated overnight at $4^{\circ} \mathrm{C}$ with agitation. The lipopeptides were then collected by centrifugation at $8,000 \mathrm{rpm}$, for $20 \mathrm{~min}$ at $4^{\circ} \mathrm{C}$. The obtained pellet was suspended in distilled water and the $\mathrm{pH}$ was adjusted to 8.0 (Abouseoud, Yataghene, Amrane, \& Maachi, 2008). The lipopeptides solution was freeze-dried and used for solvent extraction, which was performed four times with tetrahydrofuran (THF). The mixture was stirred and centrifuged at $8,000 \mathrm{rpm}$, for $15 \mathrm{~min}$ at $4^{\circ} \mathrm{C}$. The organic phases recuperated were combined and concentrated in a rotary vacuum evaporator. The obtained extract was suspended in distilled water, lyophilized, and used for antioxidant activities, as well as emulsion stabilizer.

\section{3 | In vitro antioxidant activities}

The in vitro antioxidant activity was determined through five tests: DPPH radical-scavenging assay, $\beta$-carotene bleaching assay, ferrous ion-chelating activity, ferric-reducing activity, and inhibition of linoleic acid peroxidation. Antioxidant tests were carried out in triplicate and the results are mean values. The half maximal inhibitory concentration $\left(\mathrm{IC}_{50}\right.$ value) obtained at $50 \%$ of antioxidant activity (inhibition of the $\beta$-carotene bleaching, DPPH radicalscavenging activity). This value was obtained by linear regression analysis of dose-response curve plotting between antioxidant activity and concentrations.

\subsection{1 | DPPH radical-scavenging assay}

The 2, 2-diphenyl-1-picrylhydrazyl (DPPH) free radical-scavenging potential of C3 lipopeptides at different concentrations $(0.1-2 \mathrm{mg} / \mathrm{ml})$ was determined as described by Bersuder, Hole, and Smith (1998). A mixture of ethanol $(375 \mu \mathrm{l})$, DPPH solution $(125 \mu \mathrm{l})$ at a concentration of $0.02 \%$, wt/vol) and sample $(500 \mu \mathrm{l})$ was prepared under stirring and incubated in darkness for $30 \mathrm{~min}$ at room temperature. Then the absorbance was measured at $517 \mathrm{~nm}$ against methanol. The DPPH radical-scavenging activity was calculated by the following equation: 
DPPH radical-scavenging activity $(\%)=\frac{A_{\text {control }}+A_{\text {blank }}-A_{\text {sample }}}{A_{\text {control }}} \times 100$

$A_{\text {control }}$ : the absorbance of the control reaction (containing all reagents except lipopeptides), $A_{\text {blank }}$ : the absorbance of lipopeptides (containing all reagents except the DPPH solution), and $A_{\text {sample }}$ is the absorbance of lipopeptides with the DPPH solution. BHA (2.0 mM) was used as positive standard.

\subsection{2 | $\beta$-carotene bleaching assay}

The effect of $\mathrm{C} 3$ lipopeptides in inhibition of $\beta$-carotene bleaching was studied at different concentrations $(0.025-1 \mathrm{mg} / \mathrm{ml})$ as described by Koleva, van Beek, Linssen, de Groot, and Evstatieva (2002).

The emulsion containing $0.5 \mathrm{mg}$ of $\beta$-carotene, $25 \mu \mathrm{l}$ of linoleic acid, and $200 \mu \mathrm{l}$ of Tween 40 was dissolved in $1 \mathrm{ml}$ of chloroform, which was completely evaporated in a rotator evaporator. The obtained residue was dissolved in $100 \mathrm{ml}$ of bidistilled water. Aliquots $(2 \mathrm{ml}$ ) of the $\beta$-carotene-linoleic acid emulsion were mixed with $0.5 \mathrm{ml}$ of C3 lipopeptides $(0.025-1 \mathrm{mg} / \mathrm{ml})$, incubated at $50^{\circ} \mathrm{C}$ for $2 \mathrm{hr}$, and the optical density of each sample was measured at $470 \mathrm{~nm}$. The antioxidant activity was determined in terms of $\beta$-carotene bleaching inhibition using the following equation:

$$
\beta \text {-carotene bleaching inhibition }\left[1-\left(\frac{A_{0}-A_{t}}{A_{0}^{\prime}-A_{t}^{\prime}}\right)\right] \times 100
$$

$A_{0}$ and $A_{0}^{\prime}$ are the absorbances of the test sample and the control ( $0.5 \mathrm{ml}$ of distilled water instead of sample), respectively, measured at time zero; and $A_{t}$ and $A_{t}^{\prime}$ are the absorbances of the sample and the control, respectively, measured after incubation. BHA (2.0 mM) was used as positive control.

\subsection{3 | Ferrous ion-chelating activity}

The $\mathrm{Fe}^{2+}$ chelating activity of $\mathrm{C} 3$ lipopeptides at different concentrations $(0.5-4 \mathrm{mg} / \mathrm{ml})$ was estimated as described by Carter (1971). A mixture of $50 \mu \mathrm{FeCl}_{2}$ ( $2 \mathrm{mM}$ ), $100 \mu \mathrm{l}$ of lipopeptides sample at different concentrations $(0.5-4 \mathrm{mg} / \mathrm{ml})$, and $450 \mu$ l of distilled water was prepared and incubated for $3 \mathrm{~min}$ at room temperature. Then, $200 \mu \mathrm{l}$ ferrozine $(5 \mathrm{mM})$ was added and incubated at room temperature for $10 \mathrm{~min}$. The absorbance was determined at $562 \mathrm{~nm}$. The percentage of inhibition of ferrozine- $\mathrm{Fe}^{2+}$ complex formation was calculated using the following equation:

Ferrous ion - chelating activity $(\%)=\frac{A_{\text {control }}+A_{\text {blank }}-A_{\text {sample }}}{A_{\text {control }}} \times 100$ $A_{\text {control }}$ is the absorbance of the control reaction (without lipopeptide or EDTA), $A_{\text {blank }}$ is the absorbance of the blank (without ferrozine), and $A_{\text {sample }}$ is the absorbance of the sample. EDTA was used as positive control.

\subsection{4 | Ferric-reducing activity}

The ability of C3 lipopeptides at different concentrations $(0.1-3 \mathrm{mg} / \mathrm{ml})$ to reduce iron III was determined according to the method of Yildirim, Mavi, and Kara (2001). Lipopeptides sample (0.5 ml) at different concentration was mixed with $1.25 \mathrm{ml}$ distilled water and $1.25 \mathrm{ml}$ of potassium ferricyanide solution (1\%, wt/vol). After incubation for $20 \mathrm{~min}$ at $50^{\circ} \mathrm{C}, 0.25 \mathrm{ml}$ of TCA (10\%, wt/vol) was added to the mixture, and then centrifuged at 5,000 rpm for $5 \mathrm{~min}$. The supernatant $(1.25 \mathrm{ml})$ was mixed with $1.25 \mathrm{ml}$ of distilled water and $0.25 \mathrm{ml}$ of ferric chloride $(0.1 \%, \mathrm{wt} / \mathrm{vol})$ and then the optical density was measured at $700 \mathrm{~nm}\left(\mathrm{OD}_{700 \mathrm{~nm}}\right)$.

\subsubsection{Inhibition of linoleic acid peroxidation}

The inhibition of lipid peroxidation was tested using linoleic acid in the presence of C3 lipopeptides at a concentration of $0.1 \mathrm{mg} / \mathrm{ml}$ as described by Jemil et al. (2017). A mixture containing C3 lipopeptides $(0.1 \mathrm{mg} / \mathrm{ml})$, distilled water $(2.5 \mathrm{ml})$, ethanol $(2.5 \mathrm{ml})$, and linoleic acid $(32.5 \mu \mathrm{l})$ was prepared, with a final adjusted to $6.25 \mathrm{ml}$. The mixture was incubated at $45^{\circ} \mathrm{C}$ for 9 days in dark. Lipid peroxidation was estimated via determination of the amount of thiobarbituric acid reactive substances (TBARS) like malondialdehyde (MDA). A sample $(375 \mu \mathrm{l})$ was homogenized with $150 \mu \mathrm{l}$ of TBS buffer (50 mM Tris, $150 \mathrm{mM} \mathrm{NaCl}, \mathrm{pH} 7.4$ ) and $375 \mu \mathrm{l}$ of TCA $20 \%$ (wt/wt), and then centrifuged $\left(1,000 \mathrm{~g}, 10 \mathrm{~min}, 4^{\circ} \mathrm{C}\right)$. The supernatant $(400 \mu \mathrm{l})$ was mixed with $80 \mu \mathrm{l}$ of $\mathrm{HCl}(0.6 \mathrm{M}$ ) and $320 \mu \mathrm{l}$ of Tris-TBA (Tris $26 \mathrm{mM}$; TBA $120 \mathrm{mM}$ ), and heated for $10 \mathrm{~min}$ at $80^{\circ} \mathrm{C}$. The absorbance of the resulting solution was measured at $530 \mathrm{~nm}$. Inhibition of linoleic acid peroxidation was estimated by the following equation:

$$
\text { Inhibition of linoleic acid peroxidation }=\left[1-\frac{A_{\text {sample }}}{A_{\text {control }}}\right] \times 100
$$

where $A_{\text {sample }}$ was the absorbance of the sample and $A_{\text {control }}$ was the absorbance of the control (replacing the sample by water). Vitamin $C$, a natural antioxidant, was used as a positive control.

\subsection{Antioxidant properties of lipopeptides in model food emulsions}

\subsection{1 | Preparation of emulsions and storage conditions}

Sunflower oil, free tocopherols, was used to prepare an o/w emulsion. It contains sunflower oil (10\%), Tween-20 (1\%) as emulsifier and Milli $\mathrm{Q}$ water (89\%). The $\mathrm{pH}$ of the emulsion prepared in absence and in 
presence of C3 lipopeptides is almost 3.5. Mixture was continuously sonicated (UP200S ultrasonic, Hielscher Ultrasonics GmbH, Germany) five times to ensure enough volume of emulsion. Lipopeptides C3 were added, at a final concentration of $0.025 \%$ and $0.0016 \%$ (wt/wt of emulsion), directly to the emulsion. A negative control (without lipopeptides) and a positive control (trolox, $0.0022 \% \mathrm{wt} / \mathrm{wt}$ ) were prepared using the same procedure as samples. All prepared emulsions were incubated in a dark oven with constant elliptical movement and allowed to oxidize at a temperature of $30 \pm 1^{\circ} \mathrm{C}$ during 28 days.

\subsection{2 | Determination of primary oxidation products by peroxide value (PV)}

The primary oxidation products were measured using the PV according to the ferric thiocyanate method (Frankel, 1998). The assay was performed with a drop of emulsion in the range from 0.007 to $0.013 \mathrm{~g}$, diluted with ethanol. From this solution the required amount of sample varying according to the degree of oxidation was taken in a cuvette and ethanol (96\%) was added. Ferrous chloride and ammonium thiocyanate solutions were added each in a proportion of $1.875 \%$ (vol/vol). The optical density was determined at $500 \mathrm{~nm}$. The results were expressed as $\mathrm{mg}$ hydroperoxides $/ \mathrm{kg}$ of emulsion.

$$
\mathrm{PV}=\frac{\left(\frac{\text { Abs } \times \mathrm{dil}}{m}\right)+b}{\mathrm{a}}
$$

$a=$ represents the slope of the calibration curve, Abs = absorbance, $b=$ the intercept of the calibration curve, dil = the dilution of each emulsion, $m=$ weight of the emulsion droplet.

\subsubsection{Determination of secondary oxidation products by TBARS method}

The TBARS assay was performed as described by Maqsood and Benjakul (2010) with slight modifications. A mixture of TBARS reagent and emulsion was prepared with a ratio of 1:10. Then different samples were placed immediately in an ultrasonic bath (Prolabo brand equipment, Lutterworth, UK) for $10 \mathrm{~min}$ followed by heat treatment for $10 \mathrm{~min}$ at $100^{\circ} \mathrm{C}$. The absorbance of the supernatant obtained after mixture centrifugation at $5 \mathrm{~min}$ and 4,000 rpm was measured at $531 \mathrm{~nm}$. The results were expressed as $\mathrm{mg}$ of MDA/kg of emulsion calculated using 1,1,3,3-tetraethoxypropane as standard.

\subsection{Effect of C3 lipopeptides on lipid oxidation in ground beef patties}

\subsection{1 | Preparation of ground beef patties}

The ground meat, containing antioxidants substances $0.5 \%$ (wt/wt) (lipopeptides or BHA) was mixed with salt (1.5\%, wt/wt), divided in different parts (100 g), and different patties were formed. Negative control without antioxidant was also prepared. Then each beef pattie was over wrapped with gelatin (A gelatin, $2 \%$ ), placed in plastic trays, covered with cling film, and stored at $4 \pm 1^{\circ} \mathrm{C}$ for 14 days. Samples were evaluated for lipid oxidation after different periods (1, $3,5,7,10,12$, and 14 days) of storage.

\subsection{2 | Lipid oxidation study}

The effect of C3 lipopeptides on lipid oxidation of different prepared samples was evaluated using TBARS assay (Gallego, Gordon, Segovia, \& Almajano, 2015). Each sample (1 g) was mixed with $0.5 \mathrm{ml}$ EDTA (0.3\%) to stop fat oxidation. Then, TBARS reagent $(5 \mathrm{ml})$ was added, and the content was homogenized for $1 \mathrm{~min}$ at 32,000 rpm speed using a T 18 digital ULTRA-TURRAX ${ }^{\circledR}$ (IKA, Staufen, Germany). After homogenization, the content was filtered with Whatman filter $(0.45 \mu \mathrm{m})$, then covered tubes were placed in a boiling water bath for exactly $10 \mathrm{~min}$, and then cooled for $30 \mathrm{~min}$ at room temperature. The absorbance was measured at $531 \mathrm{~nm}$. The TBARS values were expressed as $\mathrm{mg}$ of MDA/kg of meat sample calculated using 1,1,3,3-tetraethoxypropane (SigmaAldrich) as standard. TBARS determinations for each sample were performed in triplicate.

\section{6 | Cytotoxicity assay}

HEK293 cells (Human embryonic kidney 293 cells) were grown in DMEM (Dulbecco's Modified Eagle Medium) supplemented with fetal bovine serum (10\%), penicillin $(50 \mathrm{IU} / \mathrm{ml})$ and streptomycin $(50 \mathrm{mg} / \mathrm{ml})$ at $37^{\circ} \mathrm{C}$ in a humidified atmosphere $\left(5 \% \mathrm{CO}_{2}\right)$. Cell survival was assessed using the MTT assay as previously described by Mosmann (1983). Lipopeptides C3 were added at concentrations ranging from 0.03 to $0.25 \mathrm{mg} / \mathrm{ml}$ with a volume of $100 \mu \mathrm{l}$ in wells of 96 well-plate containing cells seeded at 80,000 cells $/ \mathrm{ml}$ of medium.

Control cells were supplemented with $100 \mu$ l distilled water. HEK cells were exposed to the treatment for $48 \mathrm{hr}$. After treatment, the medium was removed and replaced with $100 \mu$ l of fresh medium supplemented with $10 \mu \mathrm{l}$ of MTT solution ( $5 \mathrm{mg} / \mathrm{ml}$ in PBS). After $4 \mathrm{hr}$, SDS solution (10\%) was added. Subsequent to formazan dissolution, the optical density was evaluated at $570 \mathrm{~nm}$ using a multidetection microplate reader. The growth inhibition was expressed as follows:

$$
\text { Cell survival }(\%)=\left(A_{1} / A_{0}\right) \times 100
$$

$A_{0}$ : control absorbance, $A_{1}$ : absorbance of the treated cells.

\section{7 | Methods of analysis}

All data presented are the average of at least three measurements which deviated by not more than $5 \%$. 


\section{3 | RESULTS AND DISCUSSION}

In our previous work, Jemil et al. (2018) selected a new Gramnegative strain, identified as E. cloacae C3, as biosurfactants producer. Structural identification and characterization showed the presence of lipopeptides mixture composed of kurstakin, surfactin, and pumilacidin isoforms (Jemil et al., 2019). Gram-positive bacteria, mainly the genus Bacillus, are well known as lipopeptides producers, while Gram-negative bacteria are known as glycolipid producers (Jemil et al., 2019).

The presence of lipopeptides mixture acts in a synergic manner and could improve the biological properties of produced lipopeptides. In this study, lipopeptides are produced after $72 \mathrm{hr}$ of growth in Landy medium with a yield of $1.02 \pm 0.13 \mathrm{~g} / \mathrm{L}$ and named crude lipopeptides. Lipopeptides was then extracted with THF and a final yield reached $0.28 \pm 0.03 \mathrm{~g} / \mathrm{L}$. The obtained lipopeptides extract was used for further studies as antioxidant substance.

\section{1 | In vitro antioxidant activities}

The determinaton of antioxidant activities of mixture molecules should be evaluated using different test due to the complexity and multifunctionality of antioxidants molecules. So several methods should be used to evaluate antioxidant activity. In this study, five tests were used: DPPH free radical-scavenging method, $\beta$-Carotene bleaching assay, ferrous ion-chelating activity, ferric reducing antioxidant power (FRAP), and inhibition of linoleic acid peroxidation.

\subsection{1 | DPPH free radical-scavenging method}

Many methods are used to determine the radical-scavenging effects of antioxidants molecules. Among them, the DPPH method can be considered as the method of choice because it is fast, easy and reliable and does not require a special reaction and device.

The C3 lipopeptides exhibited effective antioxidant activity against DPPH (Figure 1) in a dose dependent manner and highest activity (80\%) was obtained at $1 \mathrm{mg} / \mathrm{ml}$, which was higher than the scavenging activity recorded for Pseudozyma hubeiensis showing $50.3 \%$ at a concentration of $10 \mathrm{mg} / \mathrm{ml}$ of the surface active compounds mannosylerythritol lipids (Takahashi, Morita, Fukuoka, Imura, \& Kitamoto, 2012). Ben Ayed et al. (2015) studied the potential of lipopeptides mixture produced by Bacillus mojavensis A21 strain, these lipopeptides showed a DPPH radical-scavenging activity of $65 \%$ at $1 \mathrm{mg} / \mathrm{ml}$. Kiran et al. (2017) showed that the scavenging activity of Nesterenkonia sp. MSA31 lipopeptide at $6 \mathrm{mg} / \mathrm{ml}$ was $65 \%$. The DPPH scavenging activity of Bacillus cereus lipopeptides was found in the range of $27 \%-63 \%$ with a concentration of $0.5-2.0 \mathrm{mg} / \mathrm{ml}$ (Basit, Rasool, Naqvi, Waseem, \& Aslam, 2018).

The amino acid composition contributes greatly to the antioxidant properties (Malomo, He, \& Aluko, 2014). Amino acids composition of C3 lipopeptides showed the presence of Leu, Glx, Asx Gly, Ala, Val and Ile with percentages of $13.54 \%, 12.47 \%, 11.39 \%, 9.0 \%$, $8.0 \%, 6.6 \%$, and $5.5 \%$, respectively (Jemil et al., 2019). These results showed clearly that C3 lipopeptides are rich on hydrophobic amino acids (glycine, alanine, valine, leucine, and isoleucine) and the negatively charged amino acids like glutamic acid and aspartic acid. In fact, the amino acids Glu or GIn are present with one residue in the structure of surfactin isoforms and two residues in kurstakin isoforms. Asp is present in the composition of surfactin and pumilacidin with one residue. His with $2.0 \%$ molar ratio is present with one residue at position 5 in the peptide moiety of kurstakin isoforms. High radical-scavenging activities of peptides are related to the high hydrophobicity (Rajapakse, Mendis, Byun, \& Kim, 2005). Nam, You, \& Kim (2008) showed that aromatic amino acids with a large side group like His (imidazole group) contribute to the antioxidant potency of peptides because they act as hydrogen donors.

\subsection{2 | $\beta$-carotene bleaching assay}

The antioxidant assay using the discoloration of $\beta$-carotene is widely used to measure the antioxidant activity of bioactive compounds. The $\beta$-carotene bleaching inhibition was tested at different concentrations and compared with BHA (Figure 2). C3 lipopeptides inhibited significantly the discoloration of $\beta$-carotene and its antioxidant activity increased with increasing sample concentration (Figure 2). The inhibition ability of C3 lipopeptides was $59.2 \%$ at $0.3 \mathrm{mg} / \mathrm{ml}$. However, lipopeptides of Bacillus amyloliquefaciens An6 showed an inhibition value of $53 \%$ and $17.15 \%$ at 5 and $1 \mathrm{mg} / \mathrm{ml}$, respectively (Ben Ayed et al., 2017).

The inhibitor concentration $\mathrm{IC}_{50}$ of $\mathrm{C} 3$ lipopeptides was estimated to be $37.5 \mu \mathrm{g} / \mathrm{ml}$, which are more effective than lipopeptides produced by B. mojavensis A21 (Ben Ayed et al., 2015) and B. methylotrophicus DCS1 (Jemil et al., 2017), showing a IC ${ }_{50}$ value of $3.7 \mathrm{mg} / \mathrm{ml}$ and $42 \mu \mathrm{g} / \mathrm{ml}$, respectively.

\subsection{3 | Ferrous ion-chelating activity}

Hydrogen peroxide and ferrous ion $\left(\mathrm{Fe}^{2+}\right)$ interaction leads to the production of the reactive oxygen species and hydroxyl free radical $(\mathrm{OH} \bullet)$, which contribute to the initiation and/or acceleration of lipid oxidation. However, this oxidation can be inhibited by many chelating agents. The $\mathrm{Fe}^{2+}$ chelating potential of $\mathrm{C} 3$ lipopeptides against $\mathrm{Fe}^{2+}$ was evaluated by measuring the iron ferrozine complex (Figure 3). C3 lipopeptides exhibited strong ferrous-chelating activity and chelated almost $57 \%$ of ferrous ions at $4 \mathrm{mg} / \mathrm{ml}$.

Metal chelation is an important antioxidant property and chelating agents are effective as secondary antioxidants because they reduce the redox potential, stabilizing therefore the oxidized form of the metal ion. The presence of some side group such as amino and carboxyl groups of the acidic and basic amino acids (Glx, Asx, Lys, $\mathrm{His}$, and Arg) have been reported to be involved in chelating metal 

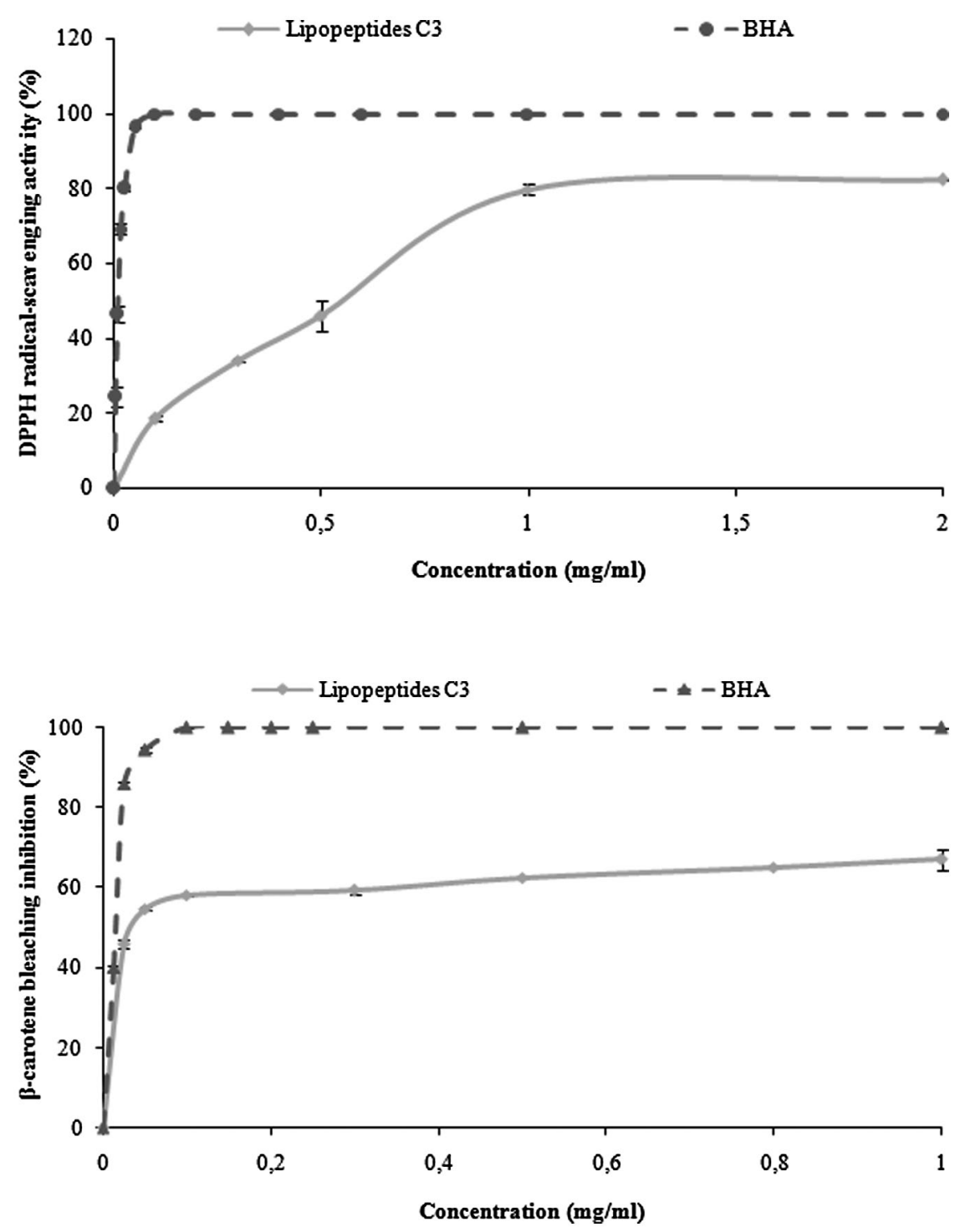

FIGURE 1 DPPH scavenging activity of $\mathrm{C} 3$ lipopeptides at different concentrations (0.1-2 mg/ml). BHA $(2.0 \mathrm{mM})$ was used as positive standard. Each value is the mean of triplicate measurements
FIGURE $2 \beta$-carotene bleaching assay of C3 lipopeptides at different concentrations (0.025-1 mg/ml). BHA $(2.0 \mathrm{mM})$ was used as positive control ions (Saiga, Tanabe, \& Nishimura, 2003). Qi et al. (2005) reported that the presence of functional groups like $\mathrm{OH},-\mathrm{COOH}, \mathrm{C}=\mathrm{O}$, and -O- contribute to the metal chelation activity. Amino acids composition of C3 lipopeptides showed the presence of these amino acids like GIx, Asx and His with percentages of $12.47 \%, 11.39 \%$, and $2.0 \%$, respectively (Jemil et al., 2019).

\subsubsection{Ferric reducing antioxidant power (FRAP)}

The reducing power potential of some molecules may serve as a significant indicator of their antioxidant potential (Gulcin, Buyukokuroglu, Oktay, \& Kufrevioglu, 2002). The FRAP mechanism is based on electron transfer rather than hydrogen atom transfer, with a reduction of $\mathrm{Fe}^{3+} /$ ferricyanide complex to the ferrous form. In this study, C3 lipopeptides and synthetic antioxidant $\mathrm{BHA}$ were evaluated for their reduction potential at different concentrations (Figure 4). The reducing capacity of C3 lipopeptides increased with increasing their concentration and reached a maximum optical density at $700 \mathrm{~nm}\left(\mathrm{OD}_{700 \mathrm{~nm}}=3.0\right)$ at a concentration of $2.0 \mathrm{mg} / \mathrm{ml}$. The reductive ability of C3 lipopeptides is higher than that of lipopeptides produced by B. mojavensis A21 (Ben Ayed et al., 2015) and surfactin lipopeptide produced by Bacillus subtilis RW-I (Yalçin \& Çavuşoğlu, 2010), which reached a maximum optical density $\left(O D_{700 \mathrm{~nm}}=2.0\right)$ at a concentration of 10 and $2.5 \mathrm{mg} / \mathrm{ml}$, respectively. Yalçin and Çavuşoğlu (2010) reported that the reductive ability could be related to the presence of hydroxyl groups in the lipopeptides molecules.

\subsection{5 | Inhibition of linoleic acid peroxidation}

In vitro lipid peroxidation inhibition activity of C3 lipopeptides was determined by assessing their ability to inhibit oxidation of linoleic acid in an emulsified model system. Antioxidant activity of C3 lipopeptides, at a concentration of $0.1 \mathrm{mg} / \mathrm{ml}$, against the peroxidation of linoleic acid during 3,6 , and 9 days of storage at $45^{\circ} \mathrm{C}$, was evaluated and compared to that of vitamin $\mathrm{C}$, which is used as a natural 
FIGURE 3 Ferrous-ion chelating activity of C3 lipopeptides at different concentrations $(0.5-4 \mathrm{mg} / \mathrm{ml})$. EDTA $(2.0 \mathrm{mM})$ was used as positive control
FIGURE 4 Ferric-reducing activity of C3 lipopeptides at different concentrations ( 0.1 to $3 \mathrm{mg} / \mathrm{ml}$ ). Values presented are the mean of triplicate analysis
FIGURE 5 Inhibition of linoleic acid peroxidation in the presence of $\mathrm{C} 3$ lipopeptides at a concentration of 0.1 $\mathrm{mg} / \mathrm{ml}$.
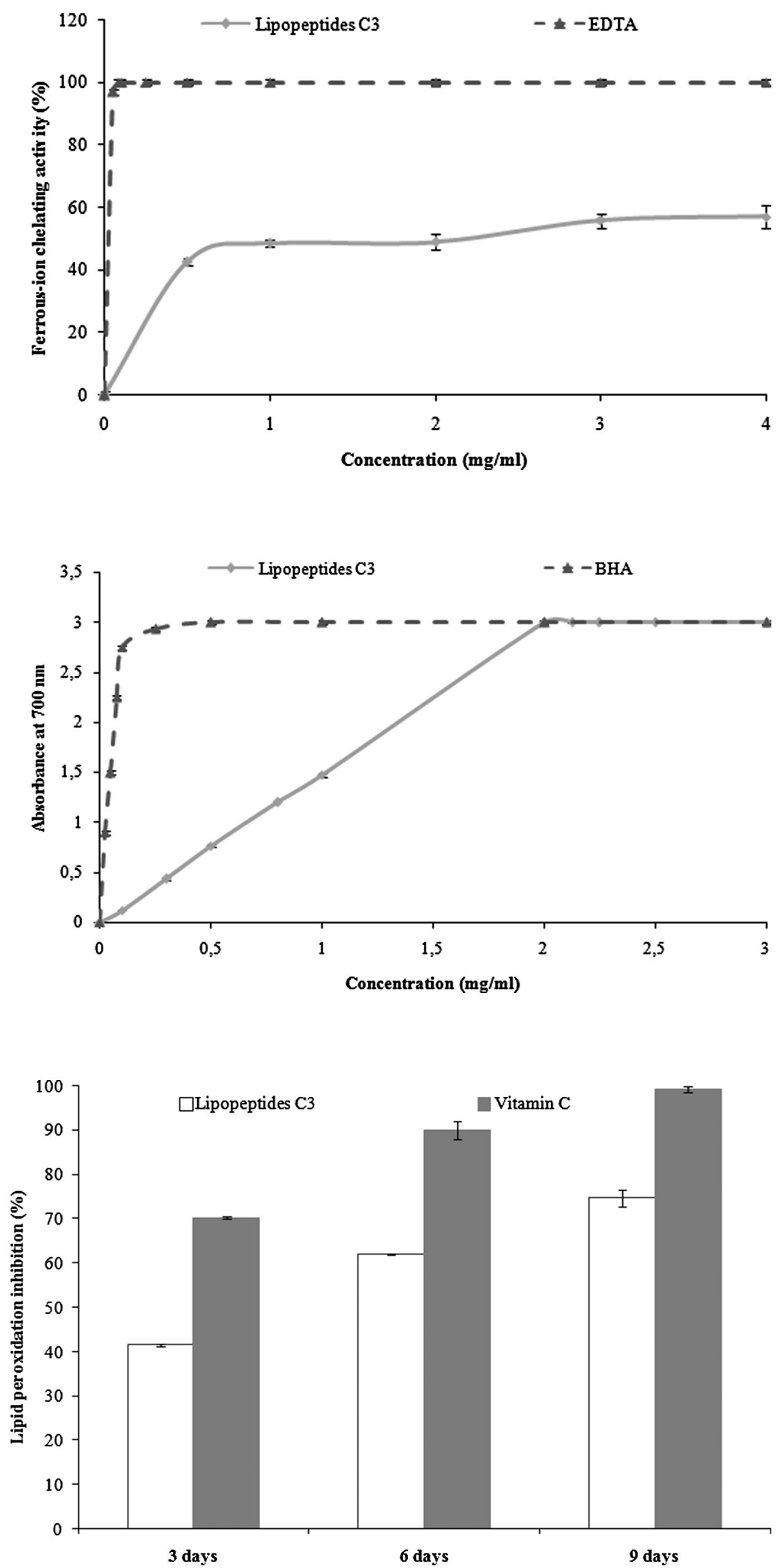
antioxidant (Figure 5). After 3 days of incubation period, C3 lipopeptides displayed a lipid peroxidation inhibition of about $41.52 \%$ and reached about $74.6 \%$ after 9 days.

In summary, the in vitro antioxidant capacities of C3 lipopeptides evaluated using different biochemical methods were found to be interesting. Many Gram-positive bacteria including different species of the genus Bacillus are reported to produce antioxidant lipopeptides like B. methylotrophicus DCS1 (Jemil et al., 2017), B. mojavenis A21 (Ben Ayed et al., 2015), B. amyloliquefaciens An6 (Ben Ayed et al., 2017), B. subtilis (Tabbene et al., 2010; Zouari et al., 2016). This is the first report on antioxidant lipopeptides produced by Enterobacter strain.

Microbial strains with ability to produce lipopeptides with diverse biological activities have potential applications in biotechnology sectors such as pharmaceutical and cosmetic industry. Also, lipopeptides are well known as antimicrobial agents and they can be used as biocontrol agents in food preservation. To prevent the deteriorative reaction, antioxidants with capacity of radicalscavenging, metal chelation, and oxygen-scavenging have been widely used in foods containing lipids (McClements \& Decker, 2006).

\subsection{Antioxidant effects of lipopeptides C3 in stored emulsions}

Besides their effects on human health through direct ingestion, one of the main applications of antioxidant molecules is their use in the food industry to avoid or delay oxidation of perishable systems. In this work, this ability has been assessed to test lipopeptides C3 as an emulsifier and stabilizer of o/w emulsions. Sunflower oil was used as a model emulsion system due to its sensitivity to oxidation and rancidity, this fact was justified by its high content of polyinsaturated fatty acids. To test the efficacy of lipopeptides $C 3$ in inhibiting oil autoxidation, PV, and TBARS, corresponding to the primary and secondary lipid oxidation products, respectively, were determined during a period of storage of 28 days.

\subsubsection{Evolution of peroxide value (PV)}

Hydroperoxides result from the reaction between unsaturated fatty acids in oil and oxygen. The evolution of PV was monitored during 28 days (Figure 6). In this study, the time required for the emulsion to reach a PV of $10 \mathrm{mg}$ hydroperoxides/kg of emulsion was determined as a measure of emulsion stability (Azman, Segovia, Martínez-Farré, Gil, \& Almajano, 2014). When the PV is greater than this value, the emulsion was considered as highly oxidized and starts to become rancid.

As shown in Figure 6 the negative control emulsion (without antioxidant product) was oxidized first and the PV increased rapidly during storage, reaching a value of $15.03 \mathrm{mg}$ hydroperoxides/ $\mathrm{kg}$ of emulsion after about 4 days of storage, followed by the positive control, trolox $(0.0022 \%$, wt/wt) which reach a level of deterioration after about 6 days with a PV of 26.48. The increasing of the concentration of C3 lipopeptides from $0.0016 \%$ to $0.025 \%$ improves the durability of the studied emulsion. In fact, the emulsion containing lipopeptides C 3 with a concentration of $0.025 \%$ remains almost stable during the studied storage period with a PV of $6.97 \mathrm{mg}$ hydroperoxides/kg of emulsion on the 28th day.

The obtained results suggest that lipopeptides C3 are able to delay and inhibit the formation of hydroperoxides, at low concentrations, during the storage of the emulsions. The inhibitory effect could be explained by the presence of amine and hydroxyl groups in the structure of lipopeptides which react with the free radicals of polyunsaturated fatty acids by giving a hydrogen atom. In addition, the hydrophobicity of these lipopeptides, which ameliorate their solubility in lipid phase, has been reported to improve their antioxidant potential (Rajapakse et al., 2005).

\subsection{2 | Evolution of TBARS values}

Secondary oxidation products result from the decomposition of hydroperoxides, which are responsible for the off-flavor, the

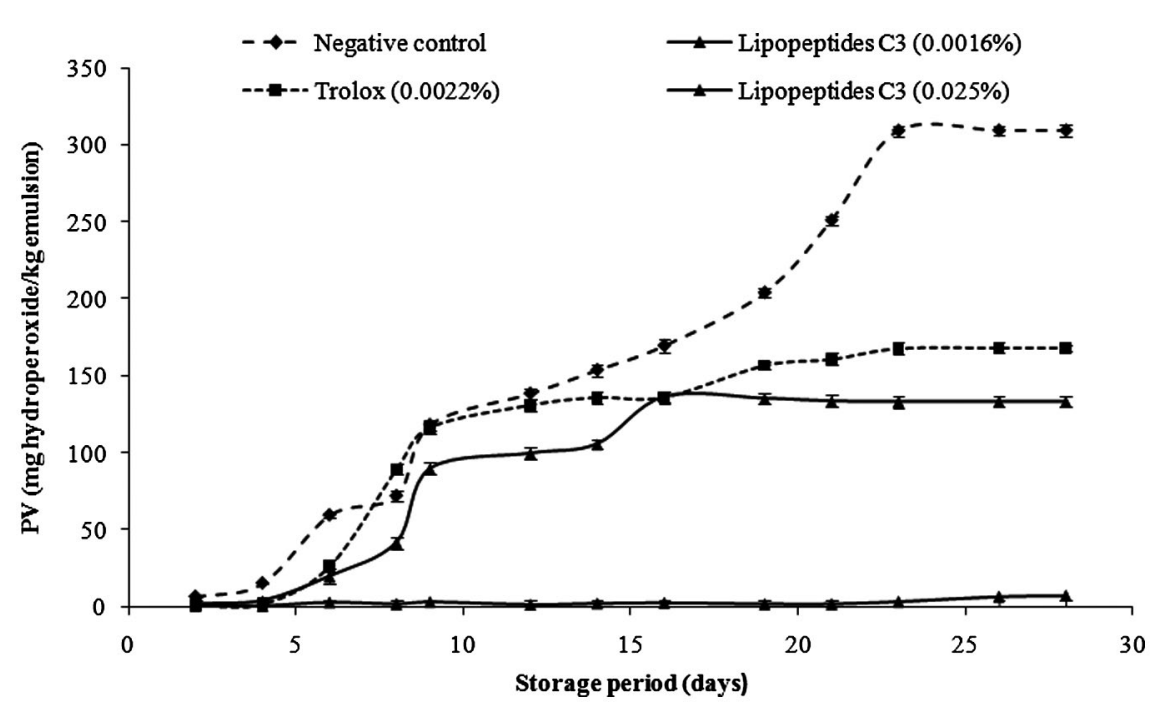

FIGURE 6 Changes in peroxide value of emulsions conserved with lipopeptides C3 at a final concentration of $0.025 \%$ and $0.0016 \%$ (w/w of emulsion). Trolox $(0.0022 \% \mathrm{w} / \mathrm{w})$ was used as positive control. The results were expressed as $\mathrm{mg}$ hydroperoxides/kg of emulsion. Lipid oxidation was occurred at $30 \pm 1^{\circ} \mathrm{C}$ during 28 days 
rancid odor and undesirable taste of oxidized edible oil. The TBARS method is widely used for determining the oxidation of fats and oils in foods (Mendes, Cardoso, \& Pestana, 2009; Wenjiao, Yongkui, Yunchuan, Junxiu, \& Yuwen, 2014). In fact, MDA compounds are formed when the concentration of hydroperoxides is appreciable in sunflower oil (Guillén \& Cabo, 2002). The acceptable limits of TBARS value in fat products was set at $1.0 \mathrm{mg} \mathrm{MDA} / \mathrm{kg}$ (Nollet \& Toldra, 2011).

In this study, the secondary oxidation products formation using the TBARS method was assessed during the the last week of emulsions storage (Figure 7). According to the results obtained, TBARS values of negative control emulsion and the emulsion containing $0.0016 \%$ lipopeptides C3 are very high. The TBARS values of the treated emulsions including $0.0022 \%$ trolox and $0.025 \%$ lipopeptides C3 were significantly lower than those of the nontreated emulsion during the 4th week of incubation. The TBARS values of emulsion containing trolox $(0.0022 \%)$ are significantly lower than those of emulsion containing lipopeptides C3 with $0.0016 \%$ concentration.

Lipopeptides C3 are able to preserve the nutritional, physical, and visual properties of the emulsion during 28 days of storage at a concentration of $0.025 \%(w t / w t)$, with a TBARS value of 0.56 $\mathrm{mg} \mathrm{MDA} / \mathrm{kg}$ of emulsion on the 28 th day.

\subsection{Effect of C3 lipopeptides on the oxidative stability of raw beef patties}

A direct method via the determination of species reacting with thiobarbituric acid (TBARS) was used to evaluate the effectiveness of the C3 lipopeptides in preventing oxidative degradation of lipids with the production of compounds, such as conjugated hydroperoxides and aldehydes. Rancidity flavor can be detected in meat products with TBARS values between 0.5 and $2.0 \mathrm{mg}$ MDA/kg (Gray
FIGURE 7 TBARS values of emulsions conserved with lipopeptides C3. Trolox $(0.0022 \% \mathrm{w} / \mathrm{w})$ was used as positive control. The results were expressed as $\mathrm{mg}$ of MDA $/ \mathrm{kg}$ of emulsion

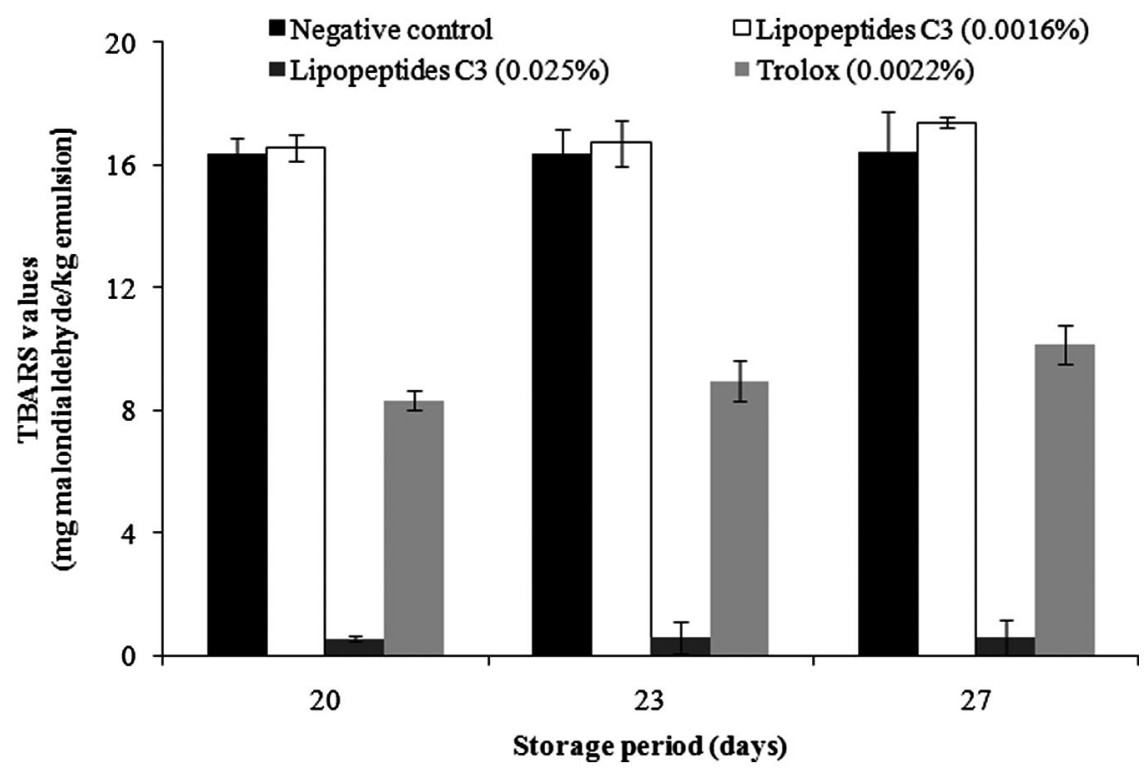

FIGURE 8 TBARS values of raw beef patties containing lipopeptides $\mathrm{C} 3$ (0.5\%) during 14 days of refrigerated storage $\left(4 \pm 1^{\circ} \mathrm{C}\right)$. BHA $(0.5 \%)$ was used as positive control. The TBARS values were expressed as mg of MDA $/ \mathrm{kg}$ of meat sample. Values presented are the mean of triplicate analyses and expressed as mean value \pm standard deviation

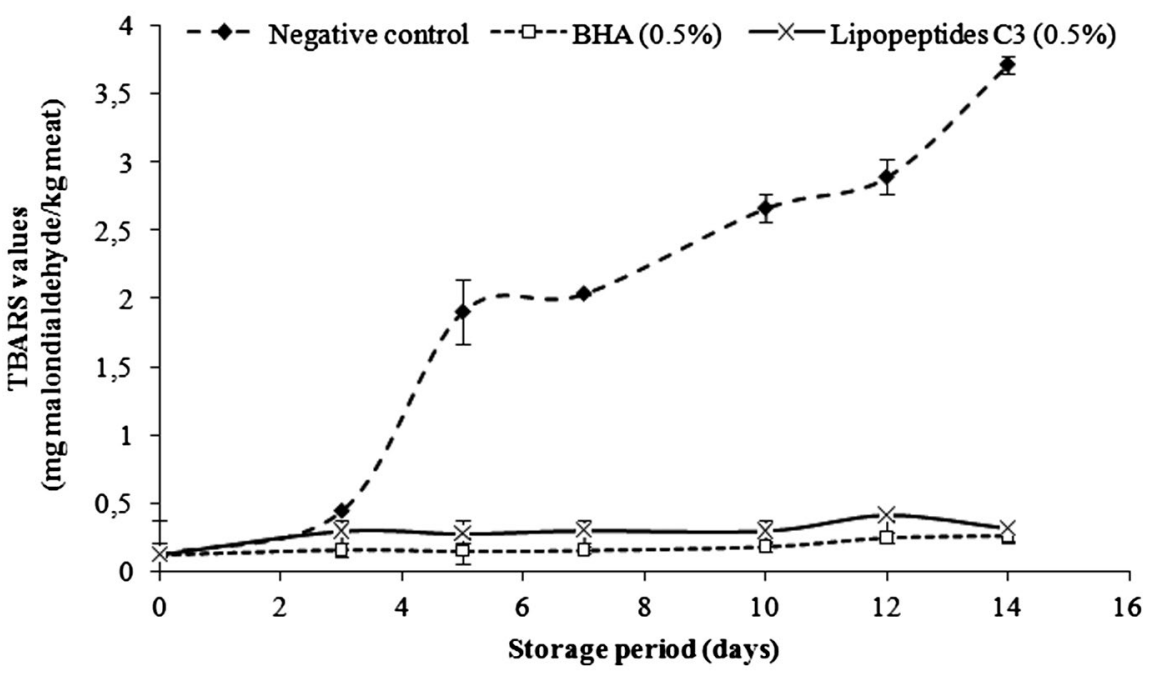




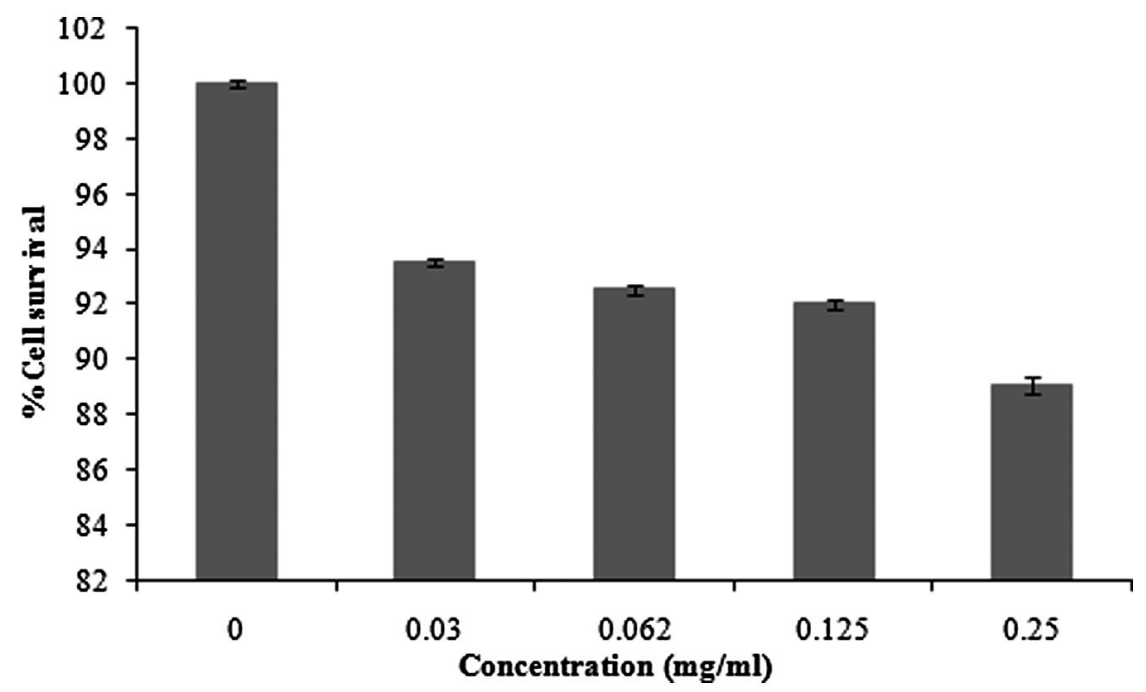

FIGURE 9 Cytotoxicity effect of lipopeptides C3 (0.03-0.25 mg/ml) on HEK293 cells line for $48 \mathrm{hr}$. MTT assay was used for determining cell viability. Each point represents a mean $\pm S D$ of three replicates per concentration

\& Pearson, 1987). The antioxidant effects of C3 lipopeptides and the synthetic antioxidant BHA in ground beef patties $(0.5 \%, \mathrm{wt} / \mathrm{wt})$ compared with the negative control are investigated (Figure 8). Natural antioxidants or C3 lipopeptides showed effective antioxidant activity against lipid oxidation, in fact the TBARS content of the beef patties treated with lipopeptides was almost similar to that of the patties treated with BHA and increased slightly over time of storage, compared with negative control (beef patties without antioxidant compound). In fact, the TBARS values reached 2.8 and $0.41 \mathrm{mg} \mathrm{MDA} / \mathrm{kg}$ of meat after 12 days, in the absence and presence of biosurfactants, respectively. The inhibition of MDA formation observed with $C 3$ lipopeptides is greater than that observed with the negative control. However, the TBARS value of patties enriched with $\mathrm{BHA}$ was $0.25 \mathrm{mg}$ MDA/kg of meat after 12 days of storage.

We can conclude that C3 lipopeptides are natural antioxidants which could be considered as alternatives to synthetic antioxidants for the preservation of meat against lipid oxidation for a long period. Furthermore, the antimicrobial and antibiofilm potential of C3 lipopeptides (Jemil et al., 2018) could be of great interest for food processing and can be used to avoid contamination in food processing areas.

\section{4 | Cytotoxicity assay}

Although, limited reports studied the toxicity of biosurfactants, they are considered generally as nontoxic substances and can be used as biological additive in some industries like pharmaceutical, cosmetic, and food (Vijayakumar \& Saravanan, 2015). In this work, the effect of lipopeptides produced by E. cloacae C3 on the viability of HEK293 cells line was investigated (Figure 9). Our results revealed that the HEK293 cells viability was not significantly inhibited by C3 lipopeptides up to a concentration of $250 \mu \mathrm{g} / \mathrm{ml}$, with cell survival about $90 \%$. Cytotoxicity of Nesterenkonia sp. lipopeptides were studied against brine shrimp, which showed no toxicity till $200 \mu \mathrm{g} / \mathrm{ml}$ (Kiran et al., 2017). Flasz, Rocha, Mosquera, and Sajo (1998) showed that biosurfactant produced by $P$. aeruginosa are nontoxic and nonmutagenic. The nontoxicity profile of C3 lipopeptides made them useful in food industries as antioxidant and emulsion stabilizer.

\section{4 | CONCLUSION}

The current study showed that the addition of C3 lipopeptides exhibited considerable antioxidant action involving several antioxidant mechanisms, including metal ion chelating, hydrogen or electron donation, and radical-scavenging during peroxidation. Further, the C3 lipopeptides showed good protection against oil oxidation (o/w emulsions) and fat in beef meat. The results of this study suggest that lipopeptides $\mathrm{C} 3$ are potential source of natural antioxidants and can be successfully used to decrease lipid oxidation and improve the shelf life of the emulsion and beef meat.

\section{ACKNOWLEDGMENTS}

This work was funded by the Ministry of Higher Education and Scientific Research, Tunisia. The authors appreciate also the collaboration and the material support of the Polytechnic University of Catalonia (UPC) and the School of Industrial Engineering of Barcelona (ETSEIB) (Chemical Engineering Department).

\section{CONFLICT OF INTEREST}

The authors have declared no conflicts of interest for this article.

\section{REFERENCES}

Abouseoud, M., Yataghene, A., Amrane, A., \& Maachi, R. (2008). Biosurfactant production by free and alginate entrapped cells of Pseudomonas fluorescens. Journal of Industrial Microbiology Biotechnology, 35, 1303-1308. https://doi.org/10.1007/s10295-008-0411-0

Azman, N. A. M., Segovia, F., Martínez-Farré, X., Gil, E., \& Almajano, M. P. (2014). Screening of antioxidant activity of Gentian lutea root and its 
application in oil-in water emulsions. Antioxidants, 3, 455-471. https ://doi.org/10.3390/antiox3020455

Bai, L., \& McClements, D. J. (2016). Formation and stabilization of nanoemulsions using biosurfactants: Rhamnolipids. Journal of Colloid and Interface Science, 479, 71-79. https://doi.org/10.1016/j. jcis.2016.06.047

Banat, I. M., Makkar, R. S., \& Cameotra, S. S. (2000). Potential commercial applications of microbial surfactants. Applied and Environmental Microbiology, 53, 495-508. https://doi.org/10.1007/s002530051648

Basit, M., Rasool, M. H., Naqvi, S. A. R., Waseem, M., \& Aslam, B. (2018). Biosurfactants production potential of native strains of Bacillus cereus and their antimicrobial, cytotoxic and antioxidant activities. Pakistan Journal of Pharmceutical Sciences, 31, 251-256.

Ben Ayed, H., Bardaa, S., Moalla, D., Jridi, M., Maalej, H., Sahnoun, Z., ... Hmidet, N. (2015). Wound healing and in vitro antioxidant activities of lipopeptides mixture produced by Bacillus mojavensis A21. Process Biochemistry, 50, 1023-1030. https://doi.org/10.1016/j. procbio.2015.02.019

Ben Ayed, H., Hmidet, N., Béchet, M., Jacques, P., \& Nasri, M. (2017). Identification and natural functions of cyclic lipopeptides from Bacillus amyloliquefaciens An6. Engineering in Life Sciences, 17, 536544. https://doi.org/10.1002/elsc.201600050

Bersuder, P., Hole, M., \& Smith, G. (1998). Antioxidants from a heated histidine-glucose model system. I. Investigation of the antioxidant role of histidine and isolation of antioxidants by high performance liquid chromatography. Journal of the American Oil Chemists' Society, 75, 181-187. https://doi.org/10.1007/s11746-001-0392-y

Carter, P. (1971). Spectrophotometric determination of serum iron at the submicrogram level with a new reagent (ferrozine). Analytical Biochemistry, 40, 450-458. https://doi. org/10.1016/0003-2697(71)90405-2

Coutte, F., Lecouturier, D., Dimitrov, K., Guez, J. S., Delvigne, F., Dhulster, P., \& Jacques, P. (2017). Microbial lipopeptide production and purification bioprocesses, current progress and future challenges. Biotechnology Journal, 12, 1600566. https://doi.org/10.1002/ biot.201600566

Desai, J. D., \& Banat, I. M. (1997). Microbial production of surfactants and their commercial potential. Microbiology and Molecular Biology Reviews, 61, 47-64.

Flasz, A., Rocha, C. A., Mosquera, B., \& Sajo, C. (1998). A comparative study of the toxicity of a synthetic surfactant and one produced by Pseudomonas aeruginosa ATCC 55925. Medical Science Research, 26, 181-185.

Frankel, E. N. (1998). Lipid oxidation. Dundee, Scotland: The Oily Press Ltd.

Gallego, M. G., Gordon, M. H., Segovia, F. J., \& Almajano, M. P. (2015). Caesalpinia decapetala extracts as inhibitors of lipid oxidation in beef patties. Molecules, 20, 13913-13926. https://doi.org/10.3390/molec ules200813913

Gharaei-Fathabad, E. (2011). Biosurfactants in pharmaceutical industry (A mini-review). American Journal of Drug Discovery and Development, 1, 58-69. https://doi.org/10.3923/ajdd.2011.58.69

Gray, J. I., \& Pearson, A. M. (1987). Rancid and warmed-over flavour. In A. M. Pearson, \& T. R. Dutson (Eds.), Advances in meat research (pp. 221-269). New York: Van Nostrand.

Guillén, M. D., \& Cabo, N. (2002). Fourier transform infrared spectra data versus anisidine values to determine oxidative stability of edible oils. Food Chemistry, 77, 503-510. https://doi.org/10.1016/ S0308-8146(01)00371-5

Gulcin, I., Buyukokuroglu, M. E., Oktay, M., \& Kufrevioglu, O. I. (2002). On the in vitro antioxidant properties of melatonin. Journal of Pineal Research, 33, 167-171. https://doi. org/10.1034/j.1600-079X.2002.20920.x

Hmidet, N., Balti, R., Nasri, R., Sila, A., Bougatef, A., \& Nasri, M. (2011). Improvement of functional properties and antioxidant activities of cuttlefish (Sepia officinalis) muscle proteins hydrolyzed by Bacillus mojavensis A21 proteases. Food Research International, 44, 27032711. https://doi.org/10.1016/j.foodres.2011.05.023

Jacques, P. (2011). Surfactin and other lipopeptides from Bacillusspp. In G. Soberón-Chávez (Ed.), Biosurfactants, MicrobiologyMonographs (Vol. 20, pp. 57-91). Berlin Heidelberg, Germany: Springer-Verlag. https://doi.org/10.1007/978-3-642-14490-5_3

Jemil, N., Ben Ayed, H., Manresa, A., Nasri, M., \& Hmidet, N. (2017). Antioxidant properties, antimicrobial and anti-adhesive activities of DCS1 lipopeptides from Bacillus methylotrophicus DCS1. BMC Microbiology, 17, 144. https://doi.org/10.1186/s12866-017-1050-2

Jemil, N., Hmidet, N., Ben Ayed, H., \& Nasri, M. (2018). Physicochemical characterization of Enterobacter cloacae $\mathrm{C} 3$ lipopeptides and their applications in enhancing diesel oil biodegradation. Process Safety and Environmental Protection, 117, 399-407. https://doi.org/10.1016/j. psep.2018.05.018

Jemil, N., Hmidet, N., Manresa, A., Rabanal, F., \& Nasri, M. (2019). Isolation and characterization of kurstakin and surfactin isoforms produced by Enterobacter cloacae C3 strain. Journal of Mass Spectrometry, 54, 7-18. https://doi.org/10.1002/jms.4302

Karlapudi, A. P., Venkateswarulu, T. C., Tammineedi, J., Kanumuri, L., Ravuru, B. K., Dirisala, V. R., \& Kodali, V. P. (2018). Role of biosurfactants in bioremediation of oil pollution-a review. Petroleum, 4, 241-249. https://doi.org/10.1016/j.petIm.2018.03.007

Kiran, G. S., Priyadharsini, S., Sajayan, A., Priyadharsini, G. B., Poulose, N., \& Selvin, J. (2017). Production of Lipopeptide Biosurfactant by a Marine Nesterenkonia sp. and its application in food industry. Frontiers in Microbiology, 8, 1138. https://doi.org/10.3389/fmicb.2017.01138

Koleva, I. I., van Beek, T. A., Linssen, J. P., de Groot, A., \& Evstatieva, L. N. (2002). Screening of plant extracts for antioxidant activity: A comparative study on three testing methods. Phytochemical Analysis, 13, 8-17. https://doi.org/10.1002/pca.611

Landy, M., Warren, G. H., Rosenman, S. B., \& Colio, L. G. (1948). Bacillomycin: An antibiotic from Bacillus subtilis active against pathogenic fungi. Proceedings of the Society for Experimental Biology and Medicine, 67, 539-541. https://doi.org/10.3181/00379727-67-16367

Liguori, I., Russo, G., Curcio, F., Bulli, G., Aran, L., Della-Morte, D., ... Abete, P. (2018). Oxidative stress, aging, and diseases. Clinical Interventions in Aging, 13, 757-772. https://doi.org/10.2147/CIA.S158513

Malomo, S. A., He, R., \& Aluko, R. E. (2014). Structural and functional properties of hemp seed protein products. Journal of Food Science, 79, 1512-1521. https://doi.org/10.1111/1750-3841.12537

Maqsood, S., \& Benjakul, S. (2010). Comparative studies of four different phenolic compounds on in vitro antioxidative activity and the preventive effect on lipid oxidation of fish oil emulsion and fish mince. Food Chemistry, 119, 123-132. https://doi.org/10.1016/j.foodc hem.2009.06.004

Marchant, R., \& Banat, I. M. (2012). Microbial biosurfactants: Challenges and opportunities for future exploitation. Trends in Biotechnology, 30, 558-565. https://doi.org/10.1016/j.tibtech.2012.07.003

McClements, D. J., \& Decker, E. A. (2006). Lipid oxidation in oil-in-water emulsions: Impact of molecular environment on chemical reactions in heterogeneous food systems. Journal of Food Science, 65, 12701282. https://doi.org/10.1111/j.1365-2621.2000.tb10596.x

Mendes, R., Cardoso, C., \& Pestana, C. (2009). Measurement of malondialdehyde in fish: A comparison study between HPLC methods and the traditional spectrophotometric test. Food Chemistry, 112, 10381045. https://doi.org/10.1016/j.foodchem.2008.06.052

Miller, J. H. (1972). Experiments in Moleculer Genetics. New York: Cold Spring Harbor Laboratory Press.

Mosmann, T. (1983). Rapid colorimetric assay for cellular growth and survival: Applicationtoproliferationand cytotoxicityassays.Journalof Immunological Methods, 65, 55-63. https://doi.org/10.1016/0022-1759(83)90303-4

Nam, K. A., You, S. G., \& Kim, S. M. (2008). Molecular and physical characteristics of squid (Todarodes pacificus) skin collagens and biological 
properties of their enzymatic hydrolysates. Journal of Food Science, 73, C249-C255. https://doi.org/10.1111/j.1750-3841.2008.00722.x

Nasri, R., Bougatef, A., Ben Khaled, H., Nedjar-Arroume, N., KarraChaabouni, M., Dhulster, P., \& Nasri, M. (2012). Antioxidant and free radical-scavenging activities of goby (Zosterises sorophiocephalus) muscle protein hydrolysates obtained by enzymatic treatment. Food Biotechnology, 26, 266-279.

Nollet, L. M. L., \& Toldra, F. (2011). Handbook of analysis of edible animal by-products (p. 471). Gent, Belgium: CRC Press.

Pekdemir, T., Çopur, M., \& Urum, K. (2005). Emulsification of crude oilwater systems using biosurfactants. Process Safety and Environmental Protection, 83, 38-46. https://doi.org/10.1205/psep.03176

Qi, H., Zhao, T., Zhang, Q., Li, Z., Zhao, Z., \& Xing, R. (2005). Antioxidant activity of different molecular weight sulfated polysaccharides from Ulva pertusa Kjellm (Chlorophyta). Journal of Applied Phycology, 17, 527-534. https://doi.org/10.1007/s10811-005-9003-9

Rajapakse, N., Mendis, E., Byun, H. G., \& Kim, S. K. (2005). Purification and in vitro antioxidative effects of giant squid muscle peptides on free radical-mediated oxidative systems. The Journal of Nutritional Biochemistry, 16, 562-569. https://doi.org/10.1016/j.jnutbio.2005.02.005

Rodrigues, L. R., Banat, I. M., Teixeira, J.A., \&Oliveira, R.(2006). Biosurfactants: Potential applications in medicine. Journal of Antimicrobial Chemotherapy, 57, 609-618. https://doi.org/10.1093/jac/dkl024

Saiga, A., Tanabe, S., \& Nishimura,T. (2003). Antioxidantactivity of peptides obtained from porcine myofibrillar proteins by protease treatment. Journal of Agricultural and Food Chemistry, 51, 3661-3667. https:// doi.org/10.1021/jf021156g

Tabbene, O., Karkouch, I., Elkahoui, S., Cosette, P., Mangoni, M. L., Jouenne, T., \& Limam, F. (2010). A new antibacterial and antioxidant S07-2 compound produced by Bacillus subtilis B38. FEMS Microbiology Letters, 303, 176-182. https://doi.org/10.1111/j.1574-6968.2009.01875.x

Takahashi, M., Morita, T., Fukuoka, T., Imura, T., \& Kitamoto, D. (2012). Glycolipid biosurfactants, mannosylerythritol lipids, show antioxidant and protective effects against $\mathrm{H}_{2} \mathrm{O}_{2}$-induced oxidative stress in cultured human skin fibroblasts. Journal of Oleo Science, 61, 457-464. https://doi.org/10.5650/jos.61.457
Vecino, X., Cruz, J. M., Moldes, A. B., \& Rodrigues, L. R. (2017). Biosurfactants in cosmetic formulations: Trends and challenges. Critical Reviews in Biotechnology, 37, 911-923. https://doi. org/10.1080/07388551.2016.1269053

Vijayakumar, S., \& Saravanan, V. (2015). Biosurfactants-types, sources and applications. Research Journal of Microbiology, 10, 181-192. https ://doi.org/10.3923/jm.2015.181.192

Wąsowicz, E., Gramza, A., Hęś, M., Jeleń, H. H., Korczak, J., Małecka, M., ... Zawirska-Wojtasiak, R. (2004). Oxidation of lipids in food. Polish Journal of Food and Nutrition Sciences, 54, 87-100. https://doi. org/10.17582/journal.sja/2016.32.3.230.238

Wenjiao, F., Yongkui, Z., Yunchuan, C., Junxiu, S., \& Yuwen, Y. (2014). TBARS predictive models of pork sausages stored at different temperatures. Meat Science, 96, 1-4. https://doi.org/10.1016/j.meats ci.2013.06.025

Yalçin, E., \& Çavuşoğlu, K. (2010). Structural analysis and antioxidant activity of a biosurfactant obtained from Bacillus subtilis RW1. Turkish Journal of Biochemistry, 35, 243-247.

Yildirim, A., Mavi, A., \& Kara, A. A. (2001). Determination of antioxidant and antimicrobial activities of Rumex crispus L. extracts. Journal of Agricultural and Food Chemistry, 49, 4083-4089. https://doi. org/10.1021/jf0103572

Zouari, R., Moalla-Rekik, D., Sahnoun, Z., Rebai, T., Ellouze-Chaabouni, S., \& Ghribi-Aydi, D. (2016). Evaluation of dermal wound healing and in vitro antioxidant efficiency of Bacillus subtilis SPB1 biosurfactant. Biomedicine \& Pharmacotherapy, 84, 878-891. https://doi. org/10.1016/j.biopha.2016.09.084

How to cite this article: Hmidet N, Jemil N, Ouerfelli M, Pilar Almajano M, Nasri M. Antioxidant properties of Enterobacter cloacae C3 lipopeptides in vitro and in model food emulsion. J 